\title{
ONLINE SYSTEM FOR MONITORING THE SAFETY OF ENGINEERING STRUCTURES
}

\author{
Burak Akpinar
}

Original scientific paper Monitoring engineering structures is a very important issue for the safety of these structures. Maintaining the safety of engineering structures depends on determining the possible deformations to the structures and taking the necessary precautions in time. In this instance, monitoring the structures became a very important problem. In this study, a prototype of web-based online monitoring system design and implementation was carried out for monitoring the movements of Fatih Sultan Mehmet Bridge which was one of Istanbul's suspended bridges. Raw observations taken by geodetic instruments can be filtered by different filtering techniques and can be analyzed by trend and FFT analysis methods. With the help of these techniques, overall monitoring of the structure was possible. Designed monitoring system can be used on different types of engineering structures such as skyscrapers and dams. With the help of this online monitoring system, project managers or any other officials, in the office, can see the observations in real time and can analyze the results while operators are working near the structure.

Keywords: health monitoring of engineering structures; online monitoring system; structural safety

Online sustav za praćenje sigurnosti tehničkih konstrukcija

Izvorni znanstveni članak Nadgledanje tehničkih konstrukcija vrlo je važno pitanje za sigurnost tih konstrukcija. Održavanje sigurnosti tehničkih konstrukcija ovisi o određivanju mogućih deformacija konstrukcije i pravodobno poduzimanju potrebnih mjera. U ovom je slučaju nadgledanje konstrukcije postao vrlo važan problem. U ovom je radu izveden i implementiran prototip konstrukcije online sustava nadgledanja zasnovan na webu u svrhu praćenja pomaka Fatih Sultan Mehmet mosta, jednog od visećih mostova u Istanbulu. Terenska zapažanja zabilježena geodetskim instrumentima mogu se filtrirati raznim tehnikama filtriranja te se analizirati metodama trend i FFT analize. Uz pomoć tih tehnika bilo je moguće izvršiti potunu kontrolu konstrukcije. Projektirani sustav nadgledanja može se primijeniti na različite vrste tehničkih konstrukcija kao što su neboderi i riječne brane. Pomoću tog online sustava, projektni menađeri ili bilo koje drugo osoblje, u uredima, mogu pratiti što se događa u realnom vremenu i analizirati retultate dok operateri rade pored konstrukcije.

Ključne riječi: konstrukcijska sigurnost; online sustav nadgledanja; praćenje stanja tehničkih konstrukcija

\section{Introduction}

Health monitoring of engineering structures is very important issue in maintaining the safety of these structures. Geodetic measurements are used widely in health monitoring applications. Depending on developments in technology, GNSS (Global Navigation and Satellite System) instruments became monitoring instruments for engineering structures such as bridges; dams; and high buildings [1, 2, 3, 4]. Besides GNSS instruments, total stations are used widely to monitor the structures $[5,6]$. Also, a combination of geodetic instruments and different sensors is used for monitoring applications.

Usually, observations are stored in the internal memory of measurement instruments or in other storage devices in the projects for monitoring the engineering structures. Observed data is transferred into a local computer and after the post-process of data, movements of the structures can be analyzed. The main purpose of monitoring the engineering structures is to determine the possible deformations or dangerous movements of the structures and to take necessary precautions on time. However, the post-process of data which is mentioned above causes waste of time and difficulties are experienced in taking necessary precautions on time.

In this study, a prototype of web-based online monitoring system design and implementation was carried out. This prototype has been actively used for monitoring the movements of Fatih Sultan Mehmet Bridge in Istanbul. Raw observations were taken by motorized total station near the structure and these observations were sent directly to a server computer via GPRS line instantly. By means of the online monitoring system, movements of the bridge were monitored and analyzed by authorized users in the office in real time. Raw observations could be filtered by using different filtering techniques, possible trend in the observations could be determined and the frequency analysis of the monitoring structure could be done using Fast Fourier Transform. Thus, while the observations were being taken near the bridge, instantaneous movements of the bridge were monitored and analyzed in the office in real time.

\section{Monitoring system layout}

The Monitoring system consisted of surveying instruments; laptops; and a GPRS/EDGE/WLAN data link for accessing the internet and web server computer monitoring software installed on it (Fig. 1). Surveying instruments sent the observations directly to laptop computers which forwarded the data to the web server via an internet connection. An internet connection could be supplied by using a mobile phone's connection or accessible WLANs.

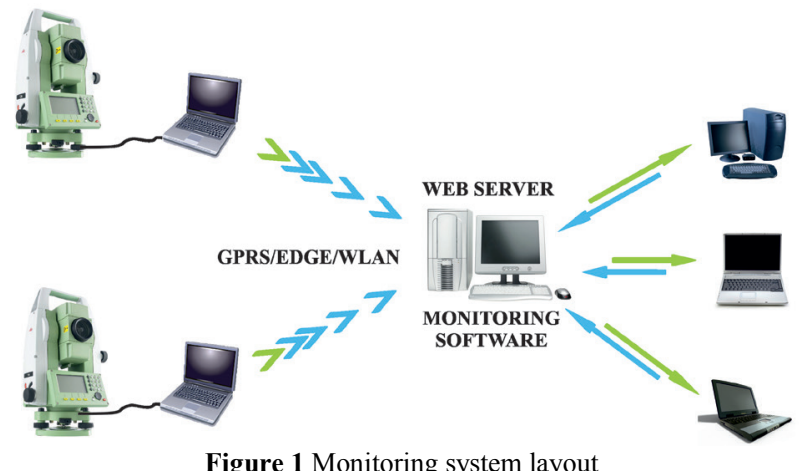

Figure 1 Monitoring system layout 
Observations of every point at different times were stored within a database server. A MySQL database was used for storing the data. MySQL was an open source database system used widely for web based applications. Because of the system's fast, reliable, scalable and easy to use characteristics, it was preferred for the monitoring system. PHP scripting language was used for processing the data and representing the results on the web page. PHP was a general purpose server side scripting language designed originally for web development in order to produce dynamic web pages.

For determining the movements of the bridge time series analysis was used. The process and analysis of the raw data consisted of three phases. Firstly, raw data was filtered using median filtering or moving average methods. The second phase was trend analysis. When a possible trend was determined from the filtered data, frequency analysis was executed by using Fast Fourier Transform (FFT) in the last phase.

\section{$3 \quad$ Time series analysis}

Characteristics of the time series can be summarized and the outstanding structure of the series can be exposed by a time series analysis which is obtained by monitoring the responses of engineering structures. So behaviors (linear, periodical) of the monitored system under different loads can be explained by a time series analysis. This process is discussed both in time domain and in frequency domain. In other words, periodical movements are discussed in frequency domain and relations between different times are discussed in time domain. Each analysis is complementary to each other and the same information gives different ideas about the characteristics of the time series.

In general time series for observations $Y\left(t_{i}\right)$ of a structure made in times $t_{i}(i=1,2,3, \ldots, N)$ may be separated into three components, trend $(Y T)$, periodical $(Y P)$ and stochastic (YST) components (Fig. 2).

$Y\left(t_{i}\right)=Y T\left(t_{i}\right)_{\text {Trend }}+Y P\left(t_{i}\right)_{\text {Periodical }}+Y S T\left(t_{i}\right)_{\text {Stochastic }}$.

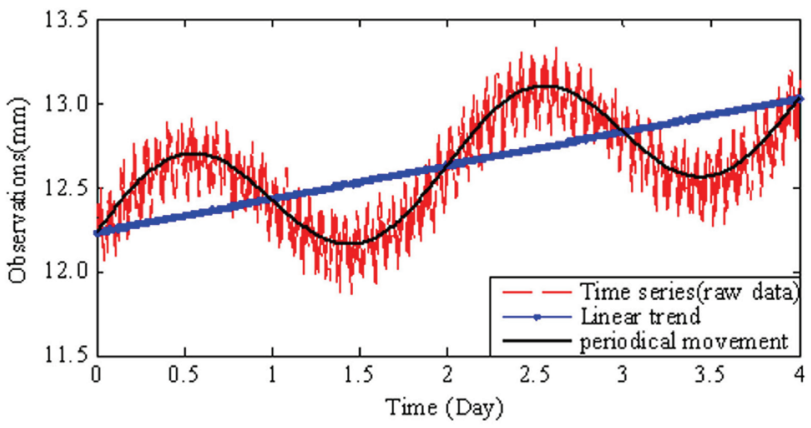

Figure $2 Y\left(t_{i}\right)$ time series (raw data), trend and periodical components of this series (example) [7]

In the analysis of time series first extraordinary observations are eliminated (e.g. outlier measurements) by drawing time axis graphic of the series and a general interpretation of the series can be made. Then a filtering procedure is applied to the series so as to partially eliminate noise effect in the series and to significantly demonstrate trend and periodical components of the series.

\subsection{Filtering techniques \\ 3.1.1 Median filtering}

Median filtering is a simple nonlinear smoother which can suppress noise whilst retaining sharp sustained changes in signal values [8]. Tukey [9] developed this technique which was applied successfully in many areas of signal estimation. In this nonlinear signal processing technique, the median of a window containing odd numbers of observations, was found by sliding the window over the entire one-dimensional signal [10]. It was an effective technique in reducing impulsive type noise.

If the window width of the filter was $2 N+1$, the filtering procedure was denoted as in Eq. (2).

$x\left(t_{i}\right)$ and $y\left(t_{i}\right)$ are the samples of the input and output sequences in times $t_{i}$ respectively.

Median filtering was applied, in many monitoring applications of engineering structures, in order to determine the observations' outliers and spikes $[11,12$, 13].

$$
\begin{aligned}
& y\left(t_{i}\right)= \\
& =\operatorname{median}\left\{x\left(t_{i-N}\right), \ldots, x\left(t_{i-1}\right), x\left(t_{i}\right), x\left(t_{i+1}\right), \ldots, x\left(t_{i+N}\right)\right\} .
\end{aligned}
$$

\subsubsection{Moving average}

The moving average is the most common filter in digital signal processing, mainly because it was the easiest digital filter to understand and to use. Despite its simplicity, the moving average filter is optimal in reducing random noise whilst retaining a sharp step response [14].

As the name implied, the moving average filter operated by averaging a number of points from the input signal to produce each point in the output signal as expressed in Eq. (3) [14].

$2 N+1, y\left(t_{i}\right)$ and $x\left(t_{i}\right)$ represents the window width of the filter, and the samples of the output and input signals in times $t_{i}$ respectively.

Laory et al. [15] and Cheng et al. [16] used moving average filtering in order to reduce the random noise on observation.

$$
y\left(t_{i}\right)=\frac{1}{2 N+1}\left(x\left(t_{i+N}\right)+x\left(t_{i+N-1}\right)+\ldots+x\left(t_{i-N}\right)\right) .
$$

\subsection{Trend and periodical components analysis}

After the filtering procedure, signal series is analyzed for the trend components. The trend component in the series represents long termed changes which can be modeled by the polynomial function in the time domain [17]

$Y T\left(t_{i}\right)_{\text {Trend }}=\sum_{k=1}^{m} c_{k} t_{i}^{k-1}$ 
In the Eq. (4), $c_{k}(k=1,2, \ldots, m)$ are the parameters depending on the order of the polynomial function. The trend component analysis is followed by the periodical component analysis.

It is considered that the periodical component in the series, which is obtained by continuously monitoring of the engineering structures, is derived from the periodical response of the structure under periodical loads. For example; long time periodical movements may be observed on engineering structures, depending on temperature changes (day-night, seasonable). Depending on traffic load, approximately the same number of vehicles passes through the suspended bridges almost every day, approximately at the same time. In particular, changes in vehicle numbers occur during nights (decreasing) and days (increasing). Depending on these changes in vehicle numbers, a lot of periodical movements (max. period is $24 \mathrm{~h}$ ) can be seen on bridges. However, vehicle type and travel speed cause short-time periodical movements and instantaneous vibrations. This analysis can be made by modeling the $Y P\left(t_{i}\right)$ signals with the use of the trigonometric function as,

$$
S P\left(t_{i}\right)_{\text {Periodical }}=\sum_{s=1}^{p}\left[a_{s} \cos \left(2 \pi f_{s} t_{i}\right)+b_{s} \sin \left(2 \pi f_{s} t_{i}\right)\right] .
$$

In the Eq. (5), the frequency $f_{s}(s=1,2, \ldots, p)$ of signal is assumed to be either known or estimated. The sum of the trend and periodical components of series in Eq. (6) can be rewritten by combining using the Eqs. (4) and (5) as;

$$
\begin{aligned}
& S\left(t_{i}\right)=\sum_{k=1}^{m} c_{k} t_{i}^{k-1}+ \\
& +\sum_{s=1}^{p}\left[a_{s} \cos \left(2 \pi f_{s} t_{i}\right)+b_{s} \sin \left(2 \pi f_{s} t_{i}\right)\right]+\operatorname{SST}\left(t_{i}\right)_{\text {Stochastic }}
\end{aligned}
$$

Unknown trend component parameters $c_{k}$ and unknown periodical component(s) parameters $a_{s}, b_{s}$ in Eq. (6) and covariance matrix of these parameters may be estimated with least square method (LSM). The square roots of the diagonal elements of this matrix are estimates of the standard deviations of parameters. With calculated $c_{k}, a_{s}$ and $b_{s}$ parameters and $m_{c k}, m_{a s}$ and $m_{b s}$ standard deviations testing values (the test statistic) are calculated for each parameter from Eq. (7).

$$
\hat{t}_{c k}=\frac{c_{k}}{m_{c k}}, \hat{t}_{a s}=\frac{a_{s}}{m_{a s}}, \hat{t}_{b s}=\frac{b_{s}}{m_{b s}} .
$$

These testing values are compared with predetermined $1-\alpha$ confidence levels and $t_{f, 1-\alpha / 2}$ confidence limit of $t$-distribution dependent on the $f$ degree of freedom. If

$$
\left|\hat{t}_{c k}\right| ;\left|\hat{t}_{a s}\right| ;\left|\hat{t}_{b s}\right|<t_{f, 1-\alpha / 2},
$$

parameters are insignificant and if $\left|\hat{t}_{c k}\right| ;\left|\hat{t}_{a s} ; ;\right| \hat{t}_{b s} \mid>t_{f, 1-\alpha / 2}$

parameters are significantly different from zero at a $1-\alpha$ confidence level.

As a result of the test, insignificant parameters are excluded from the function and this procedure is continued till all parameters become significant [6].

\subsection{Fast Fourier transform}

In order to determine significant periodical components in the function mentioned in Eq. (5) or Eq. (6), $f_{s}$ frequencies should be known. If $f_{s}$ frequencies are unknown, $f_{s}$ frequencies can be obtained from the signals $Y P\left(t_{i}\right)$ series. In the first step of the estimation, if the signals $Y\left(t_{i}\right)$ include trend components, it should be excluded from the signals. Otherwise, trend component in the series will affect the spectral analysis results and give a peak at the zero frequency [18]. A transformation of series without trend components from time domain to frequency domain is performed using fast Fourier transform (FFT). FFT of signal is defined with;

$X(k)=\sum_{t_{i}=0}^{N-1} S P\left(t_{i}\right) \mathrm{e}^{-j k \frac{2 \pi}{N} t_{i}}$,

where $N$ is the number of the observation. For $0 \leq k \leq N-1$, the calculation of $X(k)$ in Eq. (10) requires $N$ complex multiplications and $N-1$ complex sums. Computing all $N$ of the $X(k)$ values demands $N^{2}$ complex multiplications and $N^{2}-N$ complex additions. The FFT coefficients $X(k)$ are in the complex plane but this representation does not aid interpretation. Therefore, the power of the FFT coefficient is,

$P_{x x}(k)=|X(k)|^{2}$.

$P_{x x}(k)$ values are calculated as given in Eq. (11) and existing frequencies in the series are obtained by determining the density frequencies of the signal [19].

After determining the trend and periodical component(s) in the series analysis, the problem was reduced to analyzing the remaining stochastic component $\operatorname{SST}\left(t_{i}\right)_{\text {Stochastic }}$. In this study, trend and frequencies were studied by means of time series analysis. So, stochastic component analysis of the series could not be expressed in this study.

\section{Experimental setup}

The Fatih Sultan Mehmet Bridge, also known as the Second Bosporus Bridge was in Istanbul, spanning the Bosporus strait. The bridge was situated between Hisarustu on the European side and Kavacik on the Asian side (Fig. 3). It is a suspended bridge with steel pylons and hangers. The aerodynamic deck hung on double vertical steel cables. It was $1510 \mathrm{~m}$ long with a deck width of $39 \mathrm{~m}$. The bridge's main span was $1090 \mathrm{~m}$ and the bridge's clearance, from sea level, was $64 \mathrm{~m}$. 


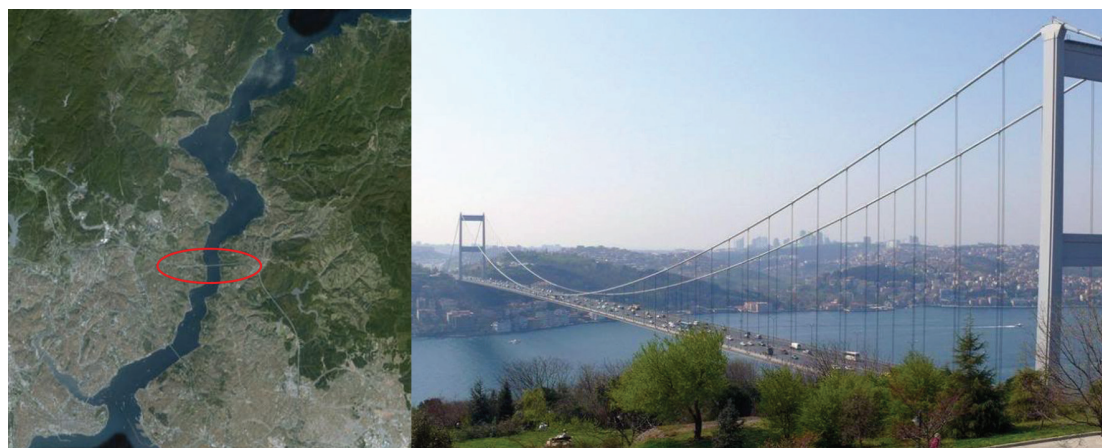

Figure 3 Fatih Sultan Mehmet Bridge

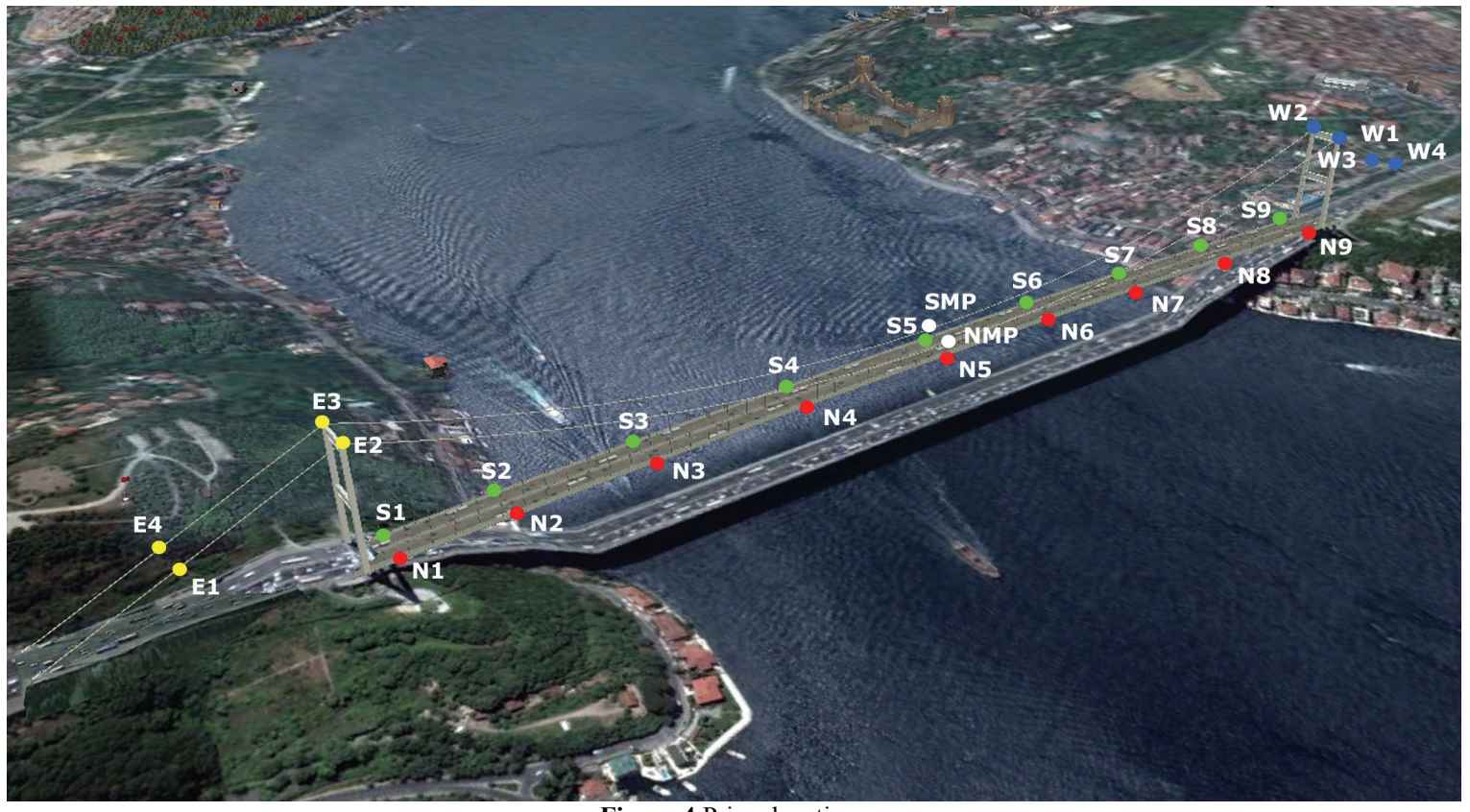

Figure 4 Prism locations

Monitoring test measurements were done on $11^{\text {th }}$ November 2007. Between 01:00 am and 10:00 am, the bridge's deck; steel towers; and main cable were measured using two robotic total stations. In this period, the bridge was closed to traffic between 02:00 am and 05:00 am.

28 prisms were established on the bridge (Fig. 4).

- 18 standard prisms on the deck cantilever

- 2 standard prisms on the main cable mid-spans

- 4 mini prisms at the each tower top points, and

- 4 mini prisms on main cable side-spans.

A local bridge coordinate system was chosen for the analysis of observations. In this coordinate system, the $X$ axis showed the span direction from the east side to the west side, the $Y$ axis showed the lateral direction from the south side to the north side and the $Z$ axis showed the vertical direction of the bridge. This coordinate system was beneficial in evaluating the observations and in describing the bridge's movement.

Two robotic total stations were used during the test measurements. Total stations had automatic target recognition (ATR) ability. The ATR total station could observe the prisms on the bridge. With the ATR, the operator needed only to point roughly, with the optical sight, to trigger a measurement. The infrared beam, transmitted from the total station telescope, was reflected back by the prism and analyzed instantly. The total station moved the telescope by fine points to the center of the prism and measured. Total stations could send the measured values to the computer via the RS232 port. Measured values on the field computer, were transmitted to the server computer via an internet connection. This internet connection could be supplied by GPRS modem or wireless network connection. In this study, a GPRS modem connection was used.

Data, transmitted from the field computer, was stored automatically by the server on a MySQL database. The measurement results could be seen instantly on designed web based software. PHP scripting language was used to process the data and to represent the results on the web page. The monitoring software and the test data can be seen on http://www.bosphorus-bridge.com/FSM/.

The raw measurement values of one point on $X, Y$ and $Z$ directions can be seen on designed web base software. Figs. 5, 6 and 7 respectively give the raw data of point S5 on $X, Y$, and $Z$ directions.

It can be seen from the figure that there is a stable line between 02:00 am and 05:00 am. As it was mentioned above the bridge was closed to traffic between 02:00 am and 05:00 am. After the 05:00 am, when the bridge was opened to traffic, movements of the bridge on all directions can be seen clearly. 


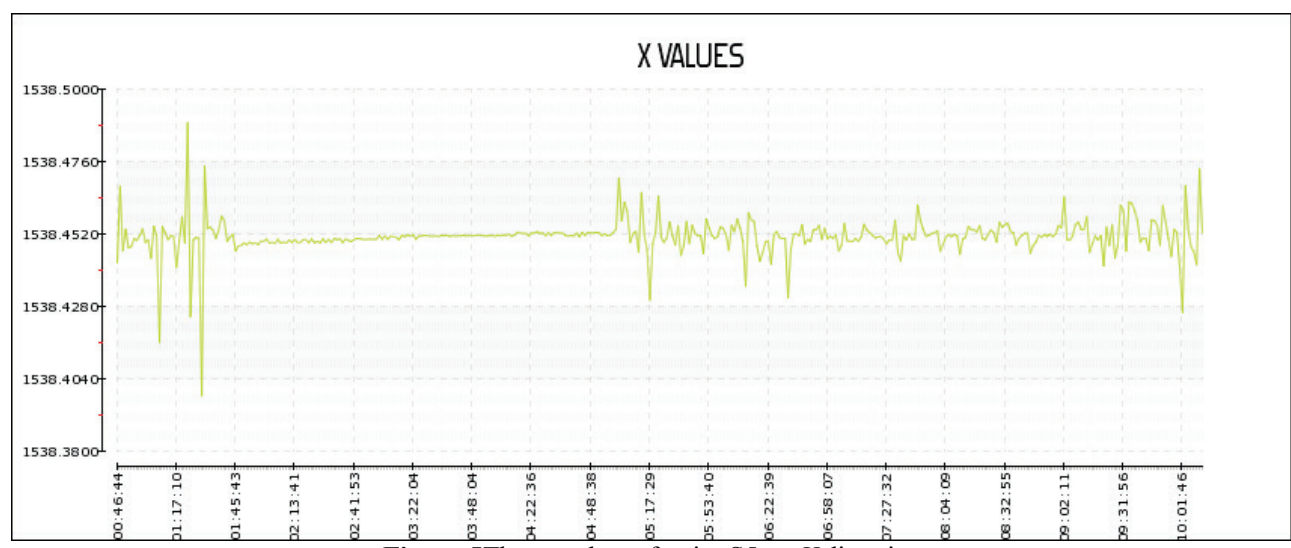

Figure 5The raw data of point S5 on $X$ direction

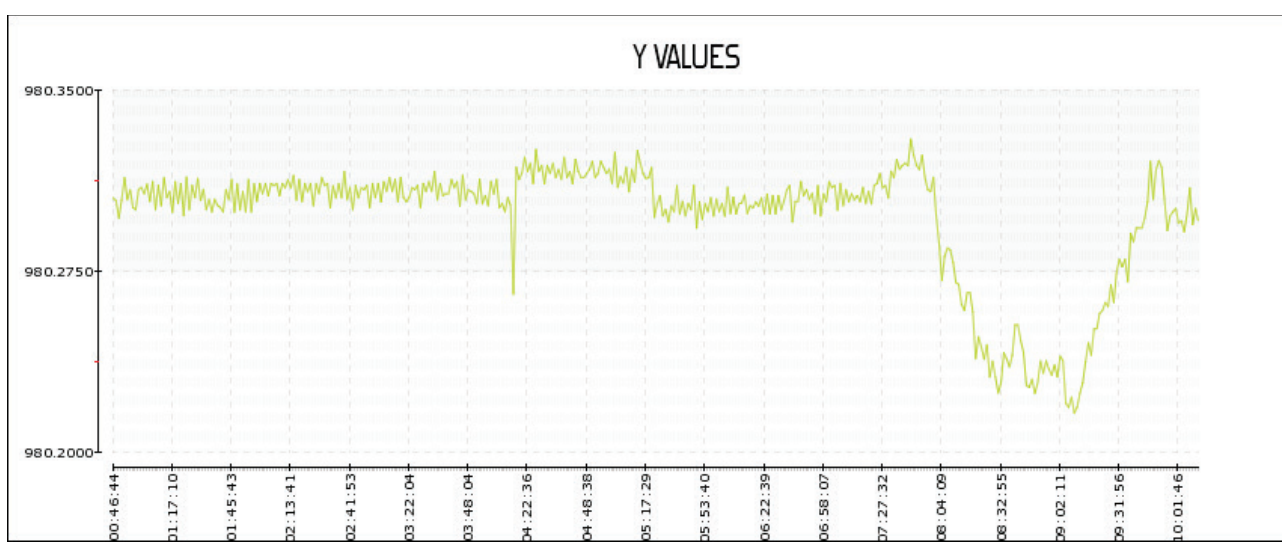

Figure 6 The raw data of point $\mathrm{S} 5$ on $Y$ direction

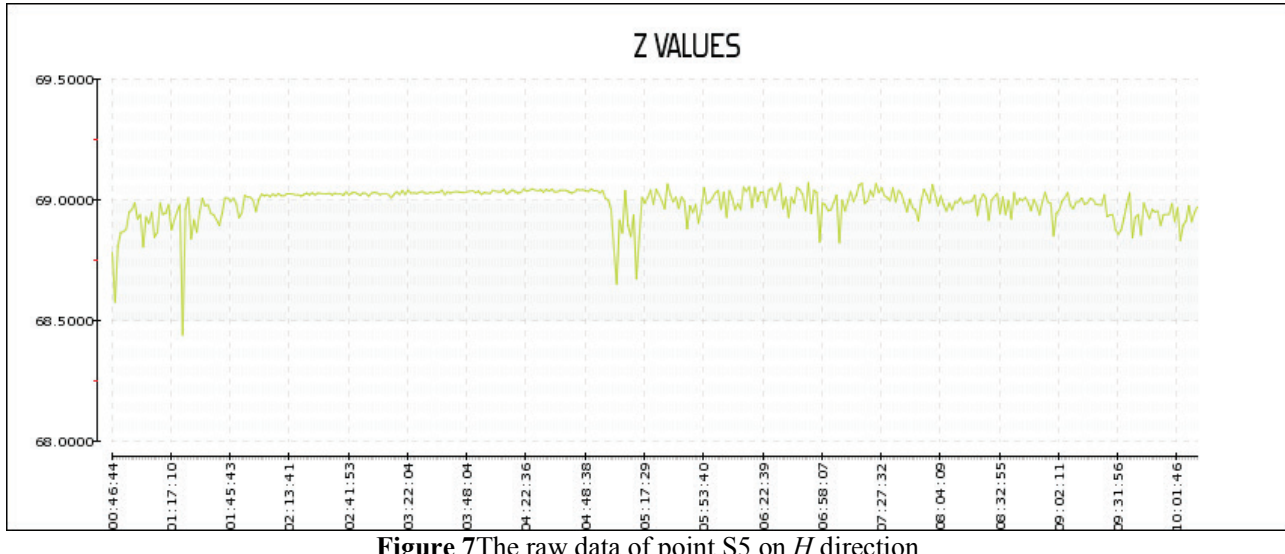

Figure 7The raw data of point S5 on $H$ direction

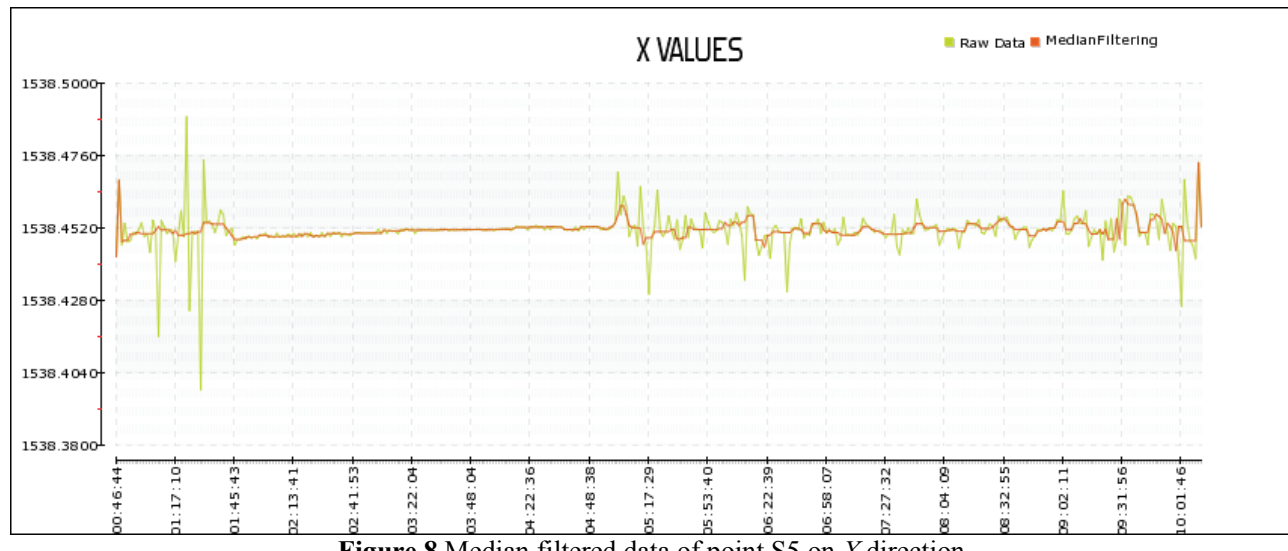

Figure 8 Median filtered data of point S5 on $X$ direction

Users could select median filtering or moving average techniques in order to remove the outliers and to smooth the data. Figs. 8, 9 and 10 give filtered data of point S5 on $X, Y$ and $Z$ directions respectively using median filtering techniques. 
Figs. 11, 12 and 13 give filtered data of point S5 on filtering techniques.

$X, Y$ and $Z$ directions respectively using moving average

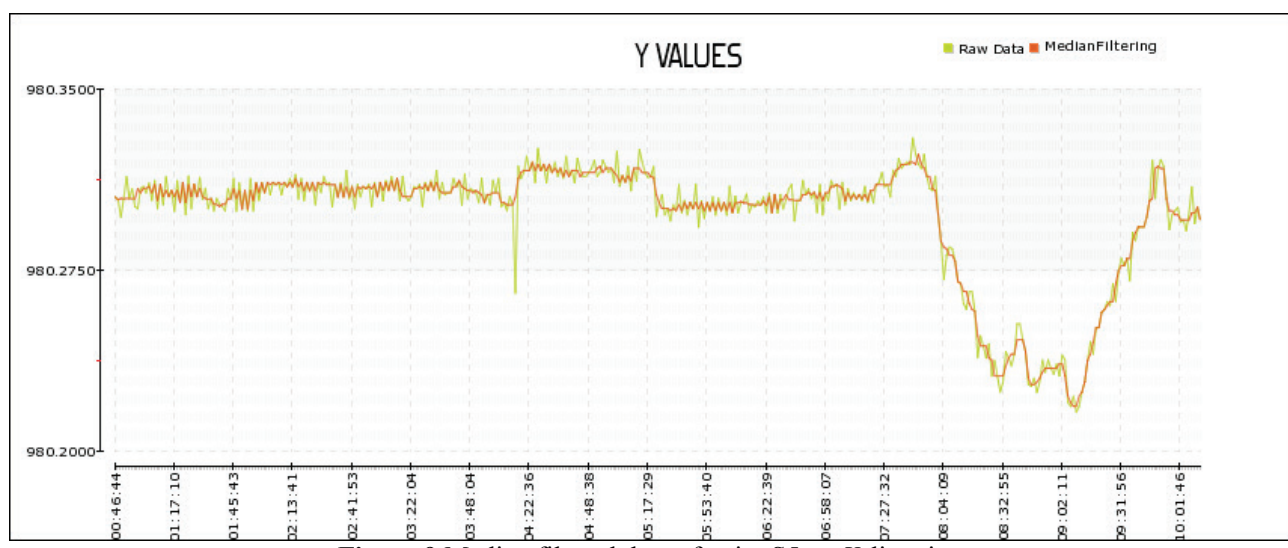

Figure 9 Median filtered data of point S5 on $Y$ direction

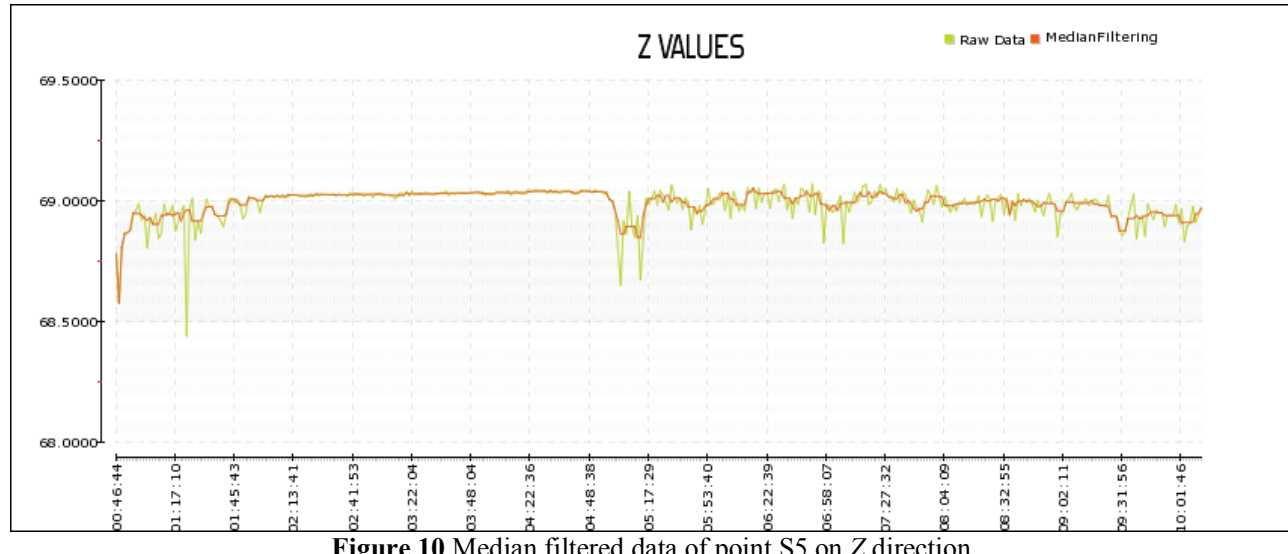

Figure 10 Median filtered data of point S5 on $Z$ direction

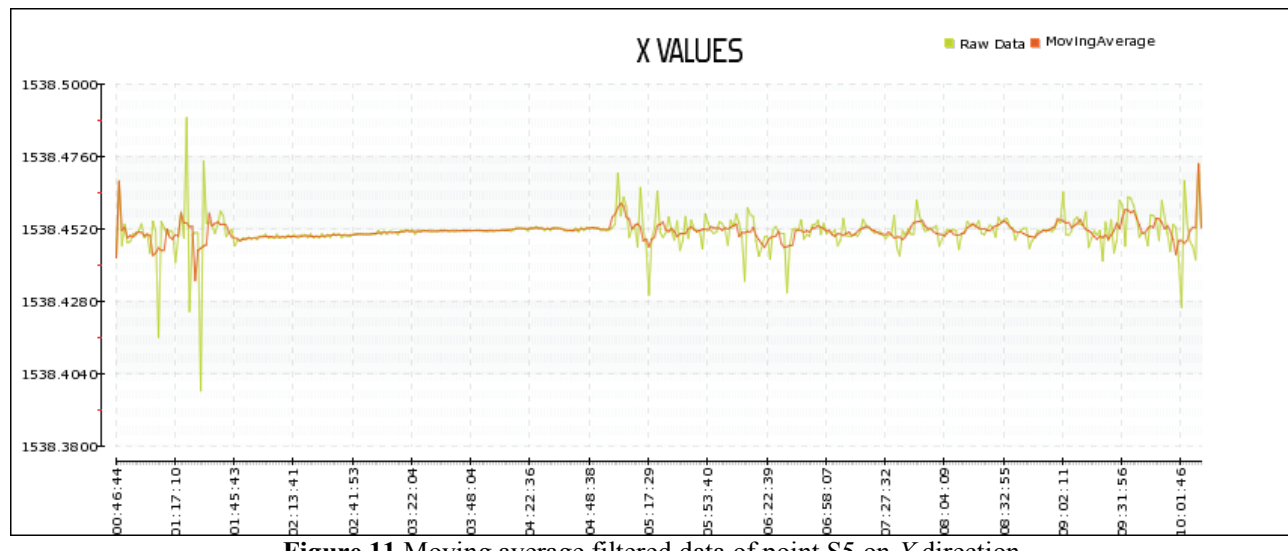

Figure 11 Moving average filtered data of point S5 on $X$ direction

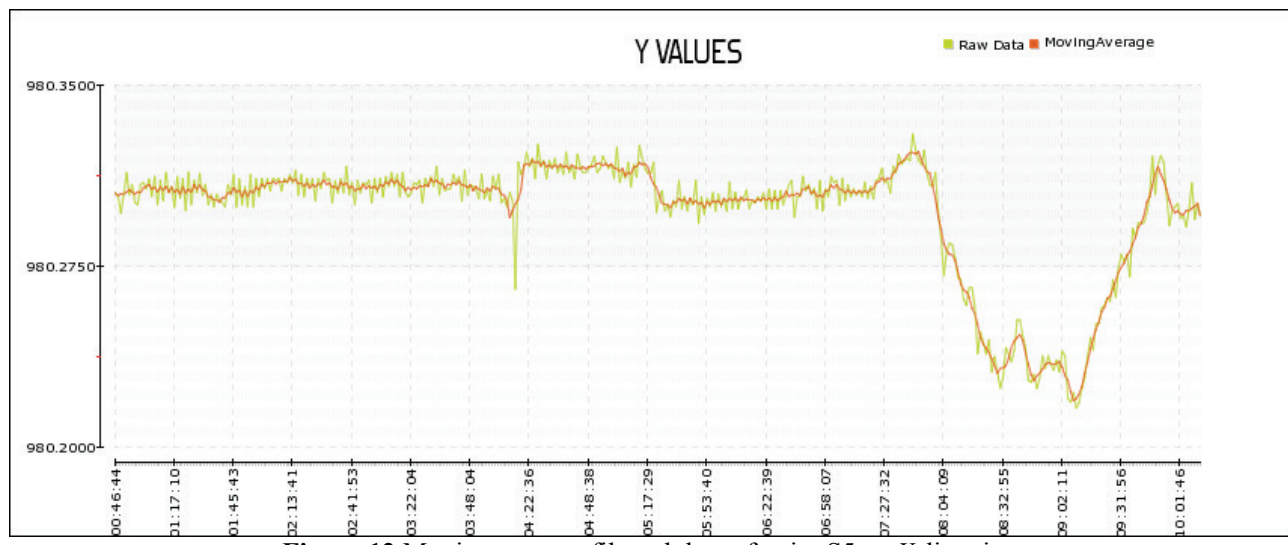

Figure 12 Moving average filtered data of point S5 on $Y$ direction 


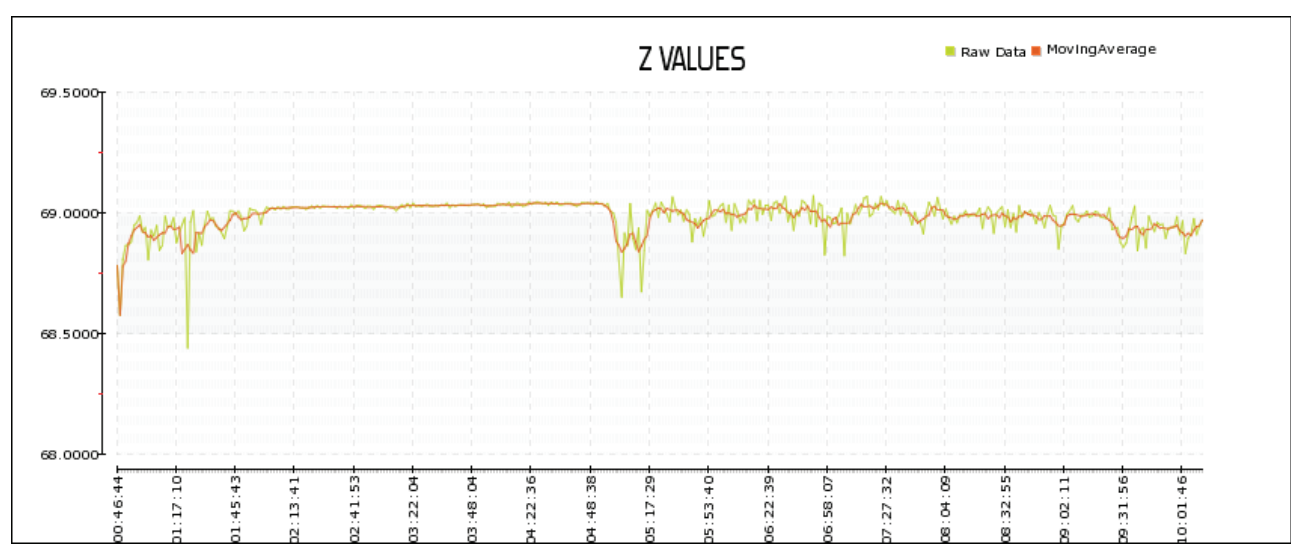

Figure 13 Moving average filtered data of point S5 on $Z$ direction

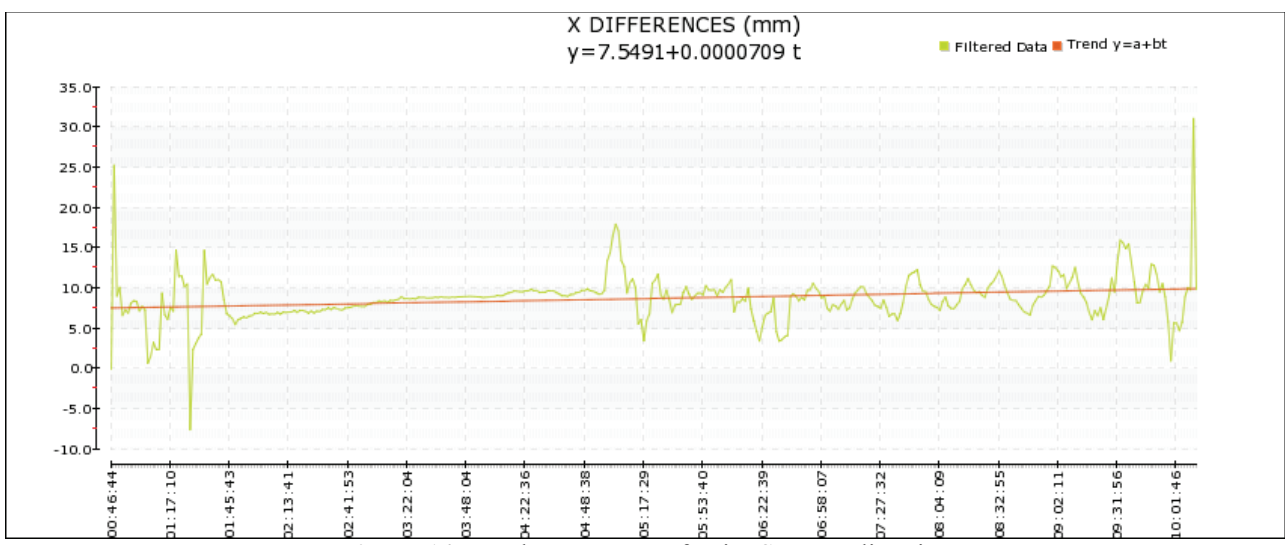

Figure 14 Trend component of point $\mathrm{S} 5$ on $X$ direction

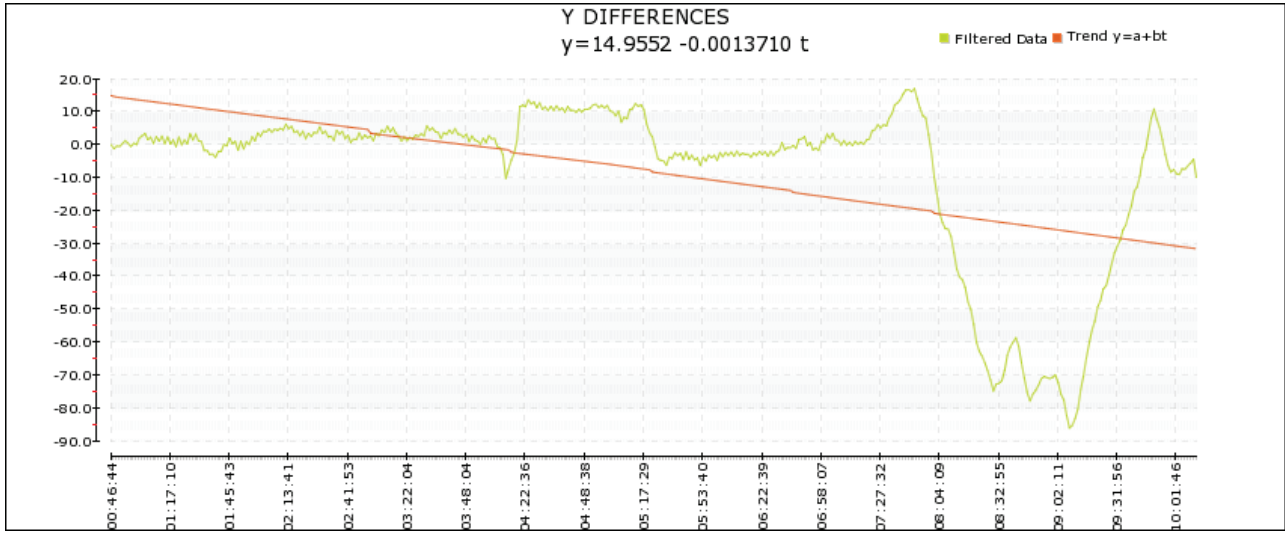

Figure 15 Trend component of point S5 on $Y$ direction

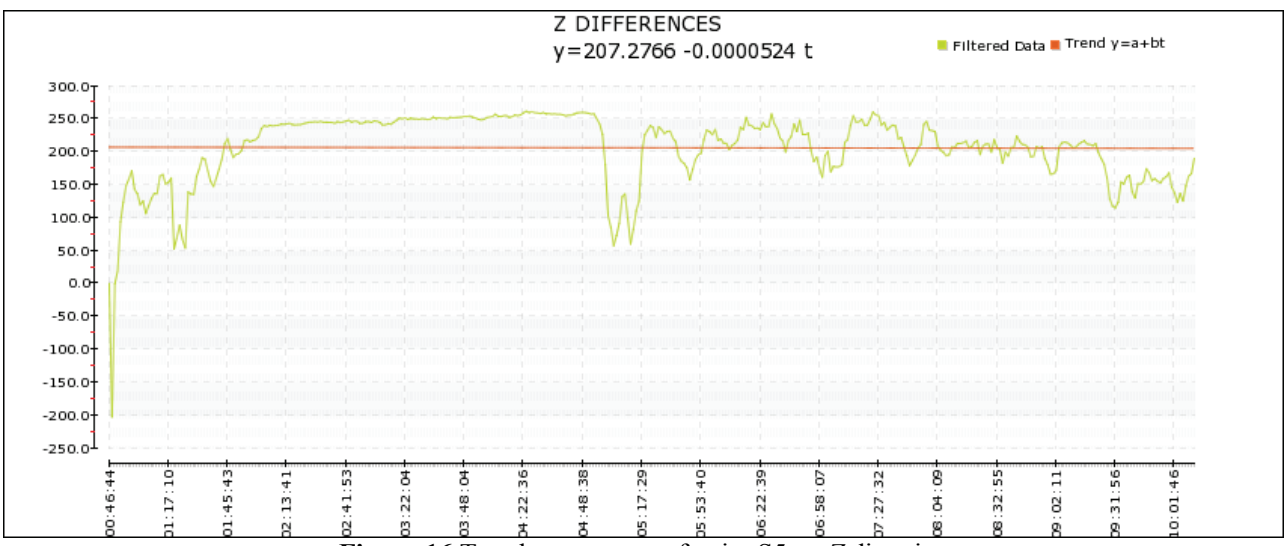

Figure 16 Trend component of point $\mathrm{S} 5$ on $Z$ direction

It can be seen from figures that similar results were determined using both filtering methods. Outliers were determined and eliminated and also data on $X, Y$ and $Z$ directions were smoothed using both methods. 
After the filtering process, it was determined if there was a trend. Figs.14, 15 and 16 give the trend component and the trend function of point S5 using $X, Y$ and $Z$ coordinate differences respectively.

Trend analysis results should be interpreted correctly taking into account the behavior of the studied engineering structure. Movements of the bridge deck in the longitudinal, lateral and vertical directions are not expected to change linearly. Yet long termed periodical movement of bridge deck arose as the linear trend component in the short termed observations. This trend component affects spectral analysis results and gives a peak at the zero frequency. Therefore in the time series analysis linear trend component, which is statistically present in the series, has been taken into account

FFT spectrum - frequency graph can be seen after the trend analysis. For investigating the frequencies on $Z$ direction only FFT analysis result for point S5 on $Z$ direction was given in Fig.17. FFT results of all points on all directions can be seen on http://www.bosphorusbridge.com/FSM.

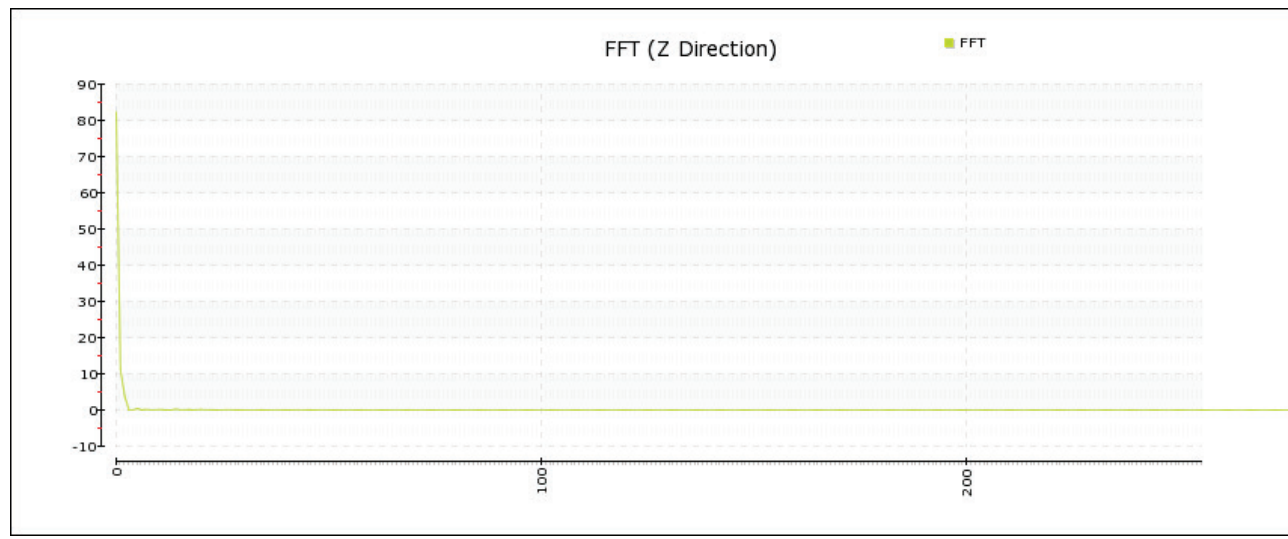

Figure 17 FFT result for point S5 on Z direction

\section{Conclusions}

Maintaining the safety of engineering structures depended on determining the possible deformations to the structures and taking necessary precautions on time. Online structural monitoring systems are very important in maintaining the safety of engineering structures. In this study, a prototype of web-based online monitoring system design and implementation was carried out. This prototype has been actively used for monitoring the movements of Fatih Sultan Mehmet Bridge in Istanbul. Only total stations were integrated to the monitoring system.

Raw observations can be filtered by using Median Filtering and Moving Average methods. After filtering process, trend analysis of the filtered observations can be done. Possible trend component in the series represents the long time changes about the structure. At the last stage, dominant frequencies, in the series, can be determined by using Fast Fourier Transform method. With the help of these techniques, overall monitoring of the structure is possible by using this online monitoring system.

Besides total stations, GNSS receivers; inclinometers; and any other measurement equipment can be integrated easily to the system. Also, designed monitoring system can be used on different type of engineering structures such as skyscrapers and dams. With the help of this online monitoring system, project managers or any other officials, in the office, can see the observations instantly and can analyze the results while operators are working near the structure.

\section{References}

[1] Li, W.; Wang, C. GPS in tailing dam deformation monitoring. // Procedia Eng. 163, (2011), pp. 1648-1657. doi:10.1016/j.proeng.2011.11.2350.

[2] Elnabwy, M. T.; Kaloop, M. R.; Elbeltagi, E. Talkha steel highway bridge monitoring and movement identification using RTK-GPS technique. // Measurement. 46, (2013), pp. 4282-4293. doi: 10.1016/j.measurement.2013.08.014.

[3] Yi, T. H.; Li, H. N.; Gu, M. Experimental assessment of high-rate GPS receivers for deformation monitoring of bridge. // Measurement. 46, (2013), pp. 420-432. doi: 10.1016/j.measurement.2012.07.018.

[4] Moschas, F.; Stiros, S. Measurement of the dynamic displacements and of the modal frequencies of a short-span pedestrian bridge using GPS and accelerometer. // Eng. Struct. 33, (2011), pp. 10-17. doi:10.1016/j.engstruct.2010.09.013

[5] Psimoulis, P. A.; Strios, S. C. A supervised learning computer-based algorithm to derive the amplitude of oscillations of structures using noisy GPS and Robotic Theodolites (RTS) records. // Computers and Structures. 92-93, (2012), pp. 337-348. doi:10.1016/j.compstruc.2011.10.019

[6] Erdogan, H.; Gulal, E. The application of time series analysis to describe the dynamic movements of suspended bridges. // Nonlinear Anal.: Real Word Appl. 10, (2009), pp. 910-927. doi: 10.1016/j.nonrwa.2007.11.013.

[7] Erdoğan, H.; Akpınar, B.; Gülal, E.; Ata, E. Monitoring the dynamic behaviors of the Bosporus Bridge by GPS during Euraisa Marathon. // Nonlinear Processes in Geophysics. 14, (2007), pp. 513-523.

[8] Stork, M. Median Filters Theory and Applications. / ELECO'2003, $3^{\text {th }}$ Int. Conf. on Electr.and Electron. Eng. Pap. December 2003, Bursa, pp. 3-25.

[9] Tukey, J. W. Exploratory Data Analysis. Addison-Wesley, Reading, Masachusetts, 1977.

[10] Doymaz, F.; Chen, J.; Romagnoli, J. A.; Palazoglu, A. A robust strategy for real-time process monitoring. // J. of Process Control. 11, (2001), pp. 343-359. 
[11] Ogaja, C.; Rizos, C.; Wang, J.; Brownjohn, J. High precision dynamic GPS system for on-line structural monitoring. $/ / 5^{\text {th }}$ Int. Symp. On Satell. Navig. Technol. \& Appl., Canberra, Australia, 24-27 July 2001, p. 35.

[12] Worden, K.; Barton, J. M. D. An Overview of Intelligent Fault Detection in Systems and Structures. // Struct. Health Monit. 3, 1(2004), pp. 85-98. doi: $10.1177 / 1475921704041866$.

[13] Bocca, M.; Eriksson, L. M.; Mahmood, A.; Jantti, R.; Kullaa, J. A Synchronized Wireless Sensor Network for Experimental Modal Analysis in Structural Health Monitoring. // Comput.-Aided Civ. and Infrastruct. Eng. 26, 7(2011), pp. 483-499. doi: 10.1111/j.1467-8667.2011.00718.x

[14] Smith, S. W. The Scientist and Engineer's Guide to Digital Signal Processing, Second Edition, ISBN:0-9660176-6-8, California Technical Publishing, USA, 1999.

[15] Laory, I.; Kripakaran, P.; Smith, I. F. C. Structural identification through continuous monitoring: data cleansing using temperature variations. // Comput. in Civ. and Build. Eng., Proc. of the Int. Conf., 30 June-2 July, Nottingham, UK, Nottingham University Press, Paper 224, (2010), p. 447. ISBN 978-1-907284-60-1.

[16] Cheng, L. K.; Liu, S. Y.; Guan, B. O.; Chung, W. H.; Chan, T. H. T.; Schaarsberg, G. et al. Dynamic load monitoring of the Tsing Ma Bridge using a high-speed FBG sensor system. // Proc. $2^{\text {nd }}$ Eur. Workshop on Struct. Health Monit., Munich, Germany 2004.

[17] Yong, C.; Chrzanowski, A. Identification of Deformation Models in Space and Time Domain. // Survey Review. 33, (1996), p. 262.

[18] Chatfield, C. The Analysis of Time Series, Chapman \& Hall/CRC, 1996

[19] Allen, R. L.; Mills, D. W. Signal Analysis, Time, Frequency, Scale, and Structure, IEEE Press, USA, 2004.

\section{Author's address}

Burak Akpinar, Asist. Prof. Dr.

Yildiz Technical University

Department of Geomatics Engineering,

Istanbul, Turkey

Tel: +90 212383 5301, Fax: +90 2123835274

E-mail: burakpinar@gmail.com 